\title{
Whole-Lung Lavage: A Successful Treatment for Restoring Acinar Ventilation Distribution in Primary Acquired Pulmonary Alveolar Proteinosis
}

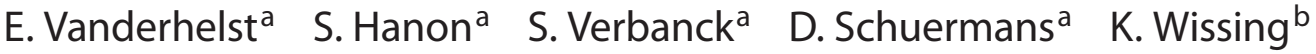 \\ F. Bonella ${ }^{c}$ W. Vincken ${ }^{a}$ \\ ${ }^{a}$ Respiratory Division and ${ }^{b}$ Department of Nephrology, University Hospital Brussels, Brussels, Belgium; \\ 'Abteilung Pneumologie, Ruhrlandklinik, Essen, Germany
}

\section{Established Facts}

- Whole-lung lavage is the common interventional treatment for pulmonary alveolar proteinosis. Standard follow-up methods include lung function parameters and radiological exams.

\section{Novel Insights}

- In addition to the standard tests, we used a state-of-the-art analysis of the multiple-breath nitrogen washout test, yielding the indices $S_{\text {cond }}$ and $S_{\text {acin }}$ as measures of ventilation heterogeneity at the level of the conductive and acinar air spaces, respectively. These parameters showed markedly abnormal acinar ventilation distribution at baseline, which returned to within the limits of normal immediately after lavage.

\section{Key Words}

Ventilation distribution - Pulmonary alveolar proteinosis • Whole-lung lavage

\section{Abstract \\ A 51-year-old active smoker with primary acquired pulmo- nary alveolar proteinosis (PAP) diagnosed by biopsy and an- ti-GM-CSF antibodies was treated safely with whole-lung la- vage (WLL). This resulted in a rapid improvement of symp- toms and arterial blood oxygenation, but not of standard lung function parameters. However, we also performed the multiple-breath nitrogen washout (MBW) test to determine}

the lung clearance index ( $\mathrm{LCl})$ as well as indices of acinar ventilation heterogeneity $\left(\mathrm{S}_{\mathrm{acin}}\right)$ and conductive ventilation heterogeneity $\left(S_{\text {cond }}\right)$. At baseline, a distinct abnormality was seen for $S_{\text {acin }}$ and $\mathrm{LCl}$, while $\mathrm{S}_{\text {cond }}$ was at the upper limit of normal for this subject. $S_{a c i n}$, in particular, was in excess of the $\mathrm{S}_{\text {acin }}$ abnormality corresponding to a 20-pack-year smoking history. Immediately after WLL, $S_{\text {acin }}$ and $S_{\text {cond }}$ both fell to within a normal range while $\mathrm{LCl}$ also decreased but remained abnormal. The $S_{\text {acin }}$ decrease was much greater than the $\mathrm{S}_{\text {cond }}$ decrease, which was to be expected after 1 week of smoking cessation at the hospital (smoking was resumed after release from hospital). A follow-up visit 7 weeks after WLL revealed a spectacular improvement on $\mathrm{CT}$ scan and im-

\section{KARGER}

Fax +4161306 1234

E-Mail karger@karger.ch

www.karger.com (c) 2012 S. Karger AG, Basel

$0025-7931 / 12 / 0841-0070 \$ 38.00 / 0$

Accessible online at:

www.karger.com/res
Eef Vanderhelst

University Hospital Brussels

Laarbeeklaan 101

BE-1090 Brussels (Belgium)

Tel. +32 477 4675, E-Mail Eef.Vanderhelst@uzbrussel.be 
provements in standard lung function. Another follow-up visit 14 weeks after WLL showed further improvements in standard lung function, and both $\mathrm{S}_{\text {acin }}$ and $\mathrm{S}_{\text {cond }}$ remained well within the normal range, and $\mathrm{LCl}$ was above the upper limit of normal. We conclude that in this patient, removal of excess surfactant by WLL resulted in a restored ventilation distribution in most of the distal air spaces.

Copyright $\odot 2012$ S. Karger AG, Basel

\section{Introduction}

Pulmonary alveolar proteinosis (PAP) is an uncommon disease characterized by the accumulation of PASpositive lipoproteinaceous material in the distal air spaces with preserved alveolar architecture [1].

We present a case of primary acquired PAP in a patient, known to have end-stage renal failure and factor $V$ Leiden deficiency, successfully treated with whole-lung lavage (WLL). The outcome was quantified with lung function tests, including a multiple breath washout (MBW) to study ventilation distribution [2]. In the adult human lung, this test distinguishes between ventilation heterogeneity in the conductive lung zone ( $\mathrm{S}_{\text {cond }}$; induced by purely convective gas transport) and ventilation heterogeneity in the acinar lung zone ( $\mathrm{S}_{\text {acin }}$; induced by diffusion-convection interaction beyond the acinar entrance).

\section{Case Report}

A 51-year-old male patient, on peritoneal dialysis because of end-stage renal failure due to biopsy-proven nephrangiosclerosis and known to have factor $\mathrm{V}$ Leiden deficiency, presented for a work-up prior to a kidney transplantation. He was an active smok- er with a 20-pack-year smoking history. Laboratory tests showed renal failure and an elevated LDH level (556 U/l). Chest CT scan revealed ground-glass opacification with a thickening of intralobular and interlobular structures, in a crazy-paving pattern (fig. 1a) and with no signs of emphysema. Pulmonary function tests showed a mild restriction ( $\mathrm{TLC}=79 \%$ predicted), but neither obstruction $\left(\mathrm{FEV}_{1} / \mathrm{FVC} 78 \%\right)$ nor air-trapping $(\mathrm{FVC}=98 \%$ pred. $)$ (table 1). Diffusing capacity was reduced [TL $\mathrm{CO}$ adjusted for hemoglobin $\left(H b \_a d j\right)=57 \%$ pred.; Hb_adj $=13.3$ g/dl]. VATS biopsy revealed preserved alveolar architecture with accumulation of lipoproteinaceous material in the air spaces (fig. 2). Anti-GMCSF antibodies were identified in a referral lab $(40 \mu \mathrm{g} / \mathrm{ml}, \mathrm{n}<10$ $\mu \mathrm{g} / \mathrm{ml}$ ), confirming the diagnosis of primary acquired PAP. Given the high rate of spontaneous remission in PAP and because the patient was asymptomatic, we decided not to start any treatment at the time of diagnosis.

One year after establishing the PAP diagnosis, the patient presented with progressive dyspnoea. He was an active smoker at the time. His LDH level was $841 \mathrm{U} / \mathrm{l}$ and chest CT revealed more pronounced reticulonodular opacities. On pulmonary function tests, both ventilatory restriction and diffusion impairment had worsened $\left[\mathrm{TLC}=62 \%\right.$ pred.; $\mathrm{TL}_{\mathrm{CO}}\left(\mathrm{Hb} \_\mathrm{adj}\right)=39 \%$ pred.]. Arterial oxygen saturation was $86 \%$. From figure 3 , it can be inferred that the most marked degree of abnormality in ventilation heterogeneity was observed for most of the distal air spaces $\left(\mathrm{S}_{\text {acin }}=184 \%\right.$ pred.) as opposed to that in the conductive air spaces $\left(S_{\text {cond }}\right.$ was at the level of its upper limit of normal for a 52-year-old never-smoker). The predicted normal $S_{\text {acin }}, S_{\text {cond }}$ and LCI values and limits of normal were based on a local cohort of 120 never-smokers (50\% males) evenly distributed across the age range 25-65 years [3].

Because of the progression of the disease, we decided to perform a WLL, using a double-lumen endotracheal tube. Twentyone 1-liter aliquots of normal saline (warmed to body temperature) were used for the left lung. The initial effluent was very milky in appearance and became progressively less opaque. The weight gain of the patient was limited and he did not need ultrafiltration. Three days after the first procedure, WLL of the right lung was performed using a total of 17 liters of normal saline. No bleeding complications occurred.

Three days after WLL, standard lung function parameters had not yet changed $\left[\mathrm{TLC}=61 \%\right.$ pred., $\mathrm{TL}_{\mathrm{CO}}\left(\mathrm{Hb} \_\right.$adj $)=38 \%$ pred.),
Fig. 1. CT scanning of the chest before (a) and after (b) WLL.
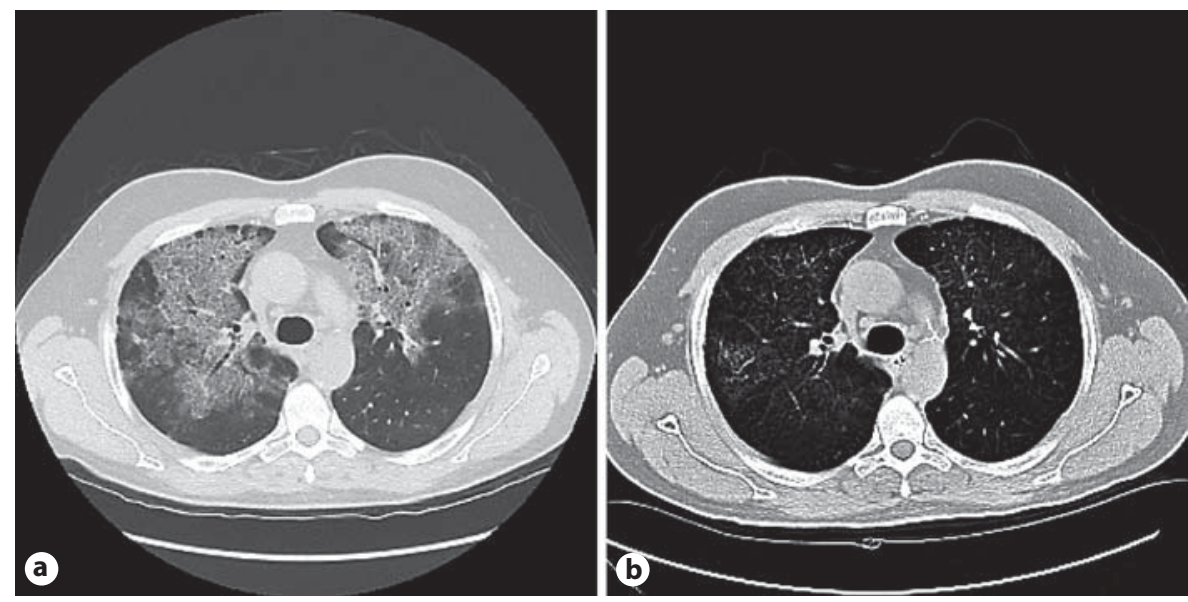

WLL Restores Acinar Ventilation Distribution in PAP
Respiration 2012;84:70-74 


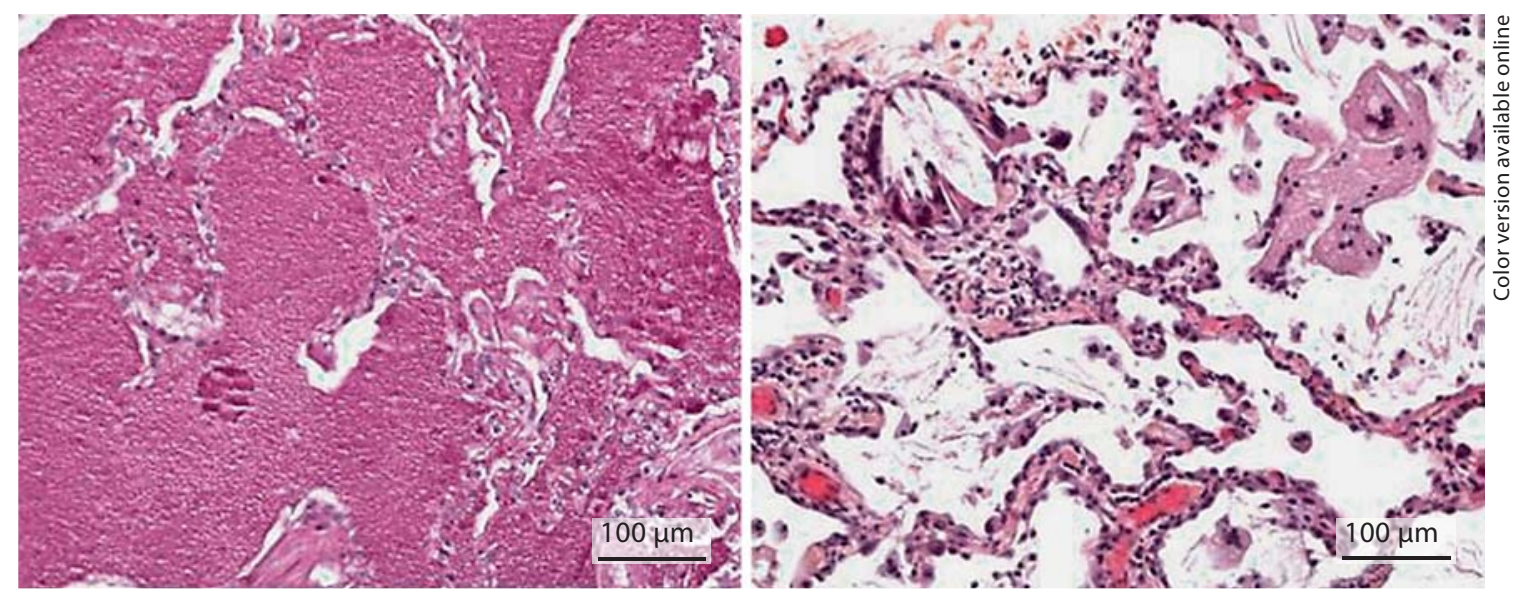

Fig. 2. VATS biopsy shows preserved alveolar architecture with accumulation of lipoproteinaceous material in the air spaces.

Table 1. Lung function values at diagnosis and up to 14 weeks post whole lung lavage

\begin{tabular}{|c|c|c|c|c|c|}
\hline & PAP diagnosis & Pre-WLL & $\begin{array}{l}\text { 1-3 Days }{ }^{b} \\
\text { post-WLL }\end{array}$ & $\begin{array}{l}7 \text { Weeks } \\
\text { post-WLL }\end{array}$ & $\begin{array}{l}14 \text { Weeks } \\
\text { post-WLL }\end{array}$ \\
\hline $\mathrm{PaO}_{2}, \mathrm{~mm} \mathrm{Hg}$ & 92 & 64 & 90 & & \\
\hline $\mathrm{SaO}_{2}, \%$ & 94 & 86 & 94 & 98 & 98 \\
\hline $\mathrm{LDH}, \mathrm{U} / \mathrm{l}$ & 556 & 841 & 972 & 575 & \\
\hline FEV $1, \%$ pred. & 95 & 71 & 70 & 75 & 86 \\
\hline $\mathrm{FEV}_{1}$, liters & 3.63 & 2.69 & 2.63 & 2.83 & 3.24 \\
\hline FVC, \% pred. & 98 & 66 & 66 & 73 & 85 \\
\hline $\mathrm{FEV}_{1} / \mathrm{FVC}, \%$ & 78 & 86 & 84 & 83 & 81 \\
\hline TLC, \% pred. & 79 & 62 & 61 & 75 & 79 \\
\hline TLC, liters & 5.82 & 4.59 & 4.49 & 5.55 & 5.80 \\
\hline FRC, \% pred. & 68 & 72 & 69 & 74 & 77 \\
\hline FRC, liters & 2.45 & 2.60 & 2.49 & 2.69 & 2.80 \\
\hline $\mathrm{TL}_{\mathrm{CO}}, \%$ pred. & 57 & 39 & 38 & 56 & 65 \\
\hline$S_{\text {cond }^{a}}{ }^{a}$ & & 0.056 & 0.016 & 0.029 & 0.042 \\
\hline $\mathrm{S}_{\text {acin }}{ }^{\mathrm{a}}$ & & 0.20 & 0.08 & 0.11 & 0.12 \\
\hline $\mathrm{LCI}^{\mathrm{a}}$ & & 7.45 & 7.10 & 6.90 & 7.20 \\
\hline
\end{tabular}

${ }^{\text {a }}$ Predicted values for a 52-year-old male never-smoker: $\mathrm{S}_{\text {cond }}=0.036 /$ liter, $\mathrm{S}_{\text {acin }}=0.110 /$ liter and LCI $=6.43$.

${ }^{\mathrm{b}} \mathrm{LDH}$ was measured on day 1 after the WLL and all other parameters were measured on day 3 after WLL.

while $S_{\text {acin }}$ and $S_{\text {cond }}$ had already decreased, by 60 and $29 \%$ of respective baseline values in this patient, to within the normal range. The $\mathrm{PaO}_{2}$ and oxygen saturation had also returned to normal immediately after WLL. Nine days after WLL, the patient was discharged from the hospital, no longer in need of any oxygen supplements. While he was subject to the smoking ban within the hospital, he returned to being an active smoker after hospital discharge.

Seven weeks later the patient presented for follow-up. He had not experienced any respiratory symptoms, and standard lung function parameters showed an improvement [TLC $=75 \%$ pred., $\mathrm{TL}_{\mathrm{CO}}\left(\mathrm{Hb} \_\mathrm{adj}\right)=56 \%$ pred.]. While $\mathrm{S}_{\text {acin }}$ and $\mathrm{S}_{\text {cond }}$ had increased slightly, both values were still in the normal range and very close to the predicted values for this subject (table 1, fig. 3). Arterial oxygen saturation on room air was $98 \%$. CT scan of the chest showed a spectacular decrease of the interstitial pattern (fig. 1b). After another 7 weeks, standard lung function was seen to be further improved, while $S_{\text {acin }}$ remained stable and only $S_{\text {cond }}$ continued to slightly increase, nevertheless remaining within the normal range.
Vanderhelst/Hanon/Verbanck/ Schuermans/Wissing/Bonella/Vincken 


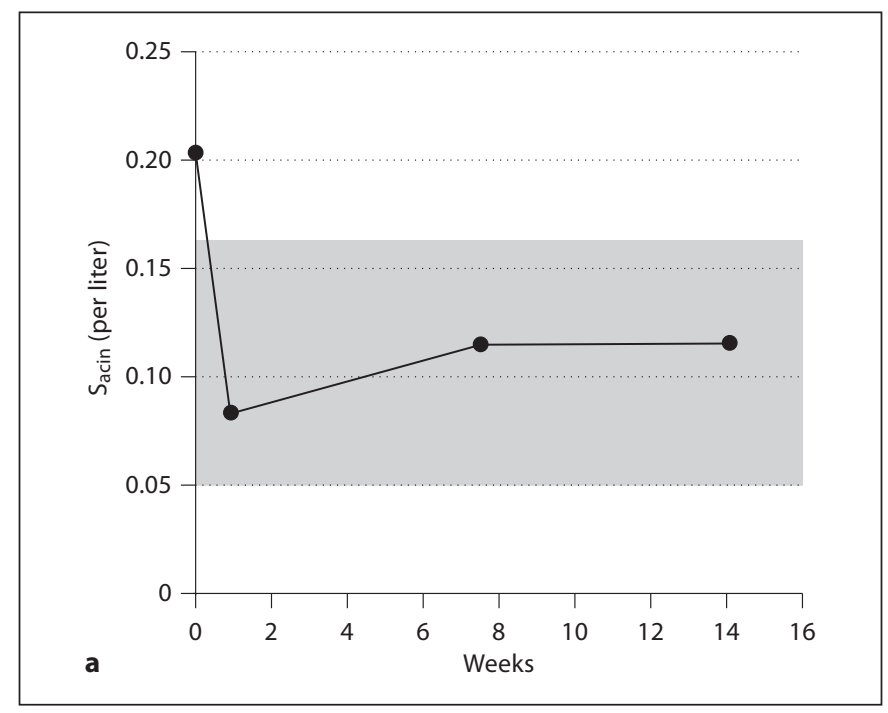

Fig. 3. $\mathrm{S}_{\text {acin }}$ at time of PAP diagnosis and at 3 time points during a 14-week follow-up; the grey area delimits the zone of normality (upper and lower limit of normal for a male subject of the same age based on a local database). $\mathbf{b} \mathrm{S}_{\text {cond }}$ during a 14-week follow-up. c LCI during a 14-week follow-up. In $\mathbf{b}$ and $\mathbf{c}$ the representation is the same as in $\mathbf{a}$.

\section{Discussion}

PAP is an uncommon disease characterized by the accumulation of PAS-positive lipoproteinaceous material in the distal air spaces, with negligible inflammation [1]. This case of primary acquired PAP in a patient with endstage renal failure was safely treated with WLL.

First performed in 1960, the success of WLL is presumed to be due to the physical removal of the excess surfactant, allowing for functional improvement. A review of 47 patients showed a favorable therapeutic response in $\mathrm{PaO}_{2}, \mathrm{P}(\mathrm{A}-\mathrm{a}) \mathrm{O}_{2}$ gradient, $\mathrm{FEV}_{1}$ and $\mathrm{TL}_{\mathrm{CO}}$ in $85 \%$ of the patients [1]. Signs of improvement are radiographic clearing, decreased LDH levels and increased
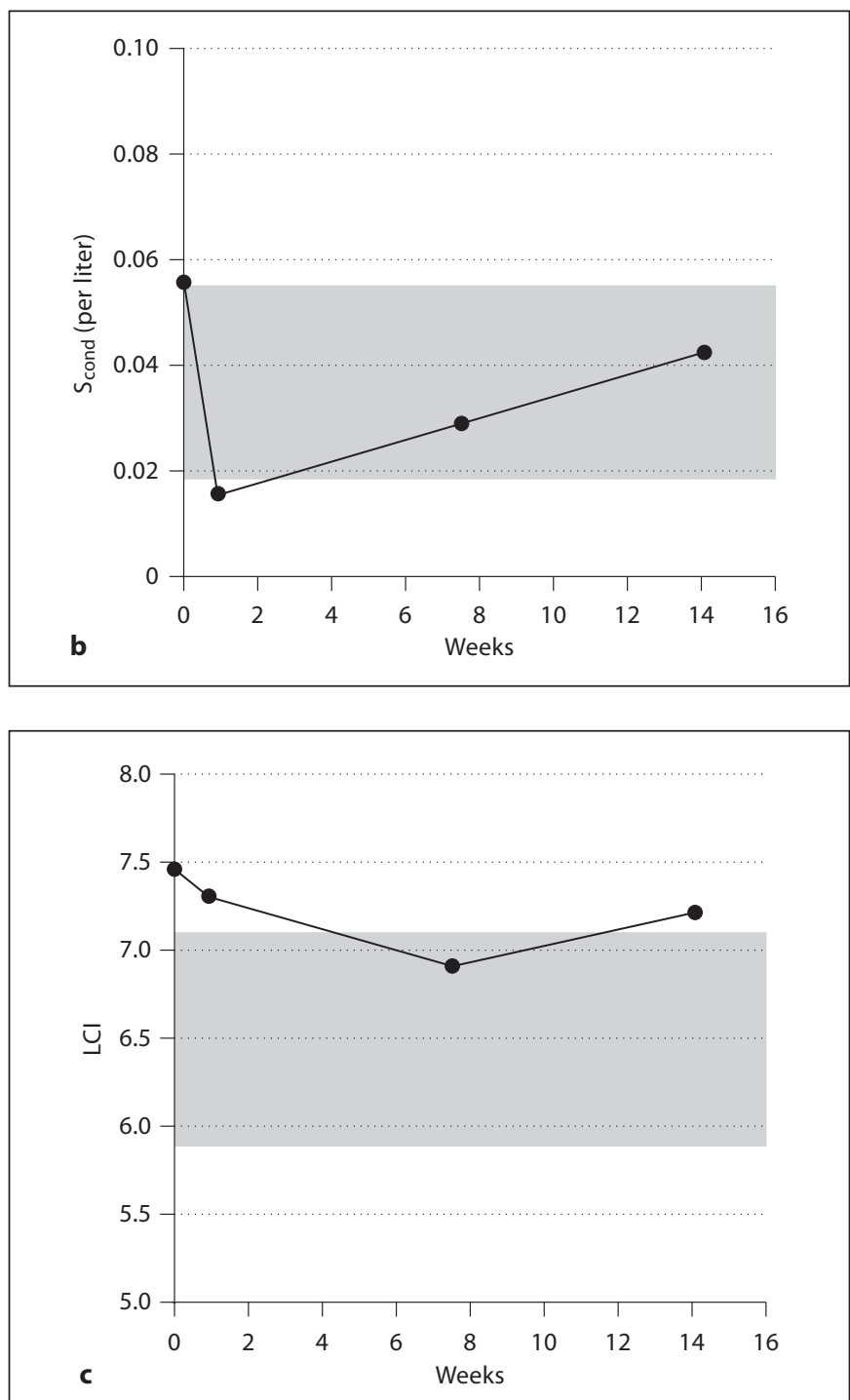

ventilation/perfusion matching. A review of 38 cases in Korea and of 21 in Italy showed consistent improvements in $\mathrm{PaO}_{2},(\mathrm{~A}-\mathrm{a}) \mathrm{O}_{2}$ and $\mathrm{TL}_{\mathrm{CO}}$ after WLL, while FVC and TLC responses were variable $[4,5]$. In our patient, we saw an improvement of TLC, $\mathrm{TL}_{\mathrm{CO}}$ and $\mathrm{PaO}_{2}$. The parameters for ventilation distribution, $S_{\text {acin }}$ and $S_{\text {cond }}$, showed an early improvement at a time when standard lung function had not yet signaled any notable change.

Lung volumes (FRC and TLC) showed a delayed improvement and, in fact, remained low throughout the observation period. This could possibly be due to an engorgement of the lympathic vessels after WLL and to the presence of some residual fluid in the alveolar spaces affecting lung compliance. Abnormal compliance of rela- 
tively large lung units may also be at the basis of the relatively high LCI values throughout the study, yet LCI could also be enhanced due to irreversible smoking-induced small airway dysfunction. Since the quantitative effect of smoking history on LCI has not been documented and it is intrinsically impossible to attribute LCI to large or small lung units, we cannot speculate on the likelihood of either explanation.

The difficulty with establishing abnormality of small airway function in this patient was that he was an active smoker. Based on a previous MBW study in smokers [2], typical $S_{\text {acin }}$ and $S_{\text {cond }}$ values in a smoker with 20 packyears amount to 125 and $132 \%$ of their normal predicted value, respectively. So for this particular patient, his personal best values for $S_{\text {acin }}$ and $S_{\text {cond }}$ could be estimated as $0.138 /$ liter and $0.048 /$ liter respectively, i.e. close to the $S_{\text {acin }}$ and $S_{\text {cond }}$ value obtained after 14 weeks (fig. 3). We cannot exclude the possibility that part of the initial $S_{\text {acin }}$ and $S_{\text {cond }}$ decrease may have been due to an episode of reduced smoking during the hospital stay. However, the expected effect of 1 week of complete smoking cessation on $S_{\text {acin }}$ and $S_{\text {cond }}$ is 16 and 13\%, respectively [6], which is considerably smaller than the 60 and $29 \%$ decrease seen in figure $3 \mathrm{a}$ and $\mathrm{b}$. While it could be argued that the increasing trend of $S_{\text {cond }}$ between 7 and 14 weeks was still in part associated with resumed smoking (after only 1 week of smoking cessation), the stabilization of $S_{\text {acin }}$ over the same time interval (fig. 3a) suggests a sustained recovery of ventilation distribution in most of the distal airway spaces of this patient.

There are no demographic or disease-related predictors of successful response to WLL [1] and approximately $15 \%$ of the patients will relapse. The observed abnormality of ventilation heterogeneity in most of the distal lung spaces and its marked response after WLL suggest that the MBW test may be a helpful additional noninvasive tool for monitoring PAP patients during follow-up in various intervention strategies.

\section{References}

$>1$ Seymour J, Presneill J: Pulmonary alveolar proteinosis. Progress in the first 44 years. Am J Respir Crit Care Med 2002;166:215235.

-2 Verbanck S, Schuermans D, Meysman M, Paiva M, Vincken W: Noninvasive assessment of airway alterations in smokers: the small airways revisited. Am J Respir Crit Care Med 2004;170:414-419.
3 Verbanck S, Thompson BR, Schuermans D, Kalsi H, Biddiscombe M, Stuart-Andrews C, Hanon S, Van Muylem A, Paiva M, Vincken W, Usmani O: Ventilation heterogeneity in the acinar and conductive zones of the normal ageing lung. Thorax 2012, E-pub ahead of print, PubMed PMID: 22544894.

4 Byun M, Kim D, Kim Y, Chung M, Shim J, Cha S, Uh S, Park C, Jeong S, Park Y, Lee H, Park M: Clinical features and outcome of idiopathic pulmonary alveolar proteinosis in Korean population. J Korean Med Sci 2010; 25:393-398.

\footnotetext{
5 Beccaria M, Luisetti M, Rodi G, Corsico A, Zoia MC, Colato S, Pochetti P, Braschi A, Pozzi E, Cerveri I: Long-term durable benefit after whole lung lavage in pulmonary alveolar proteinosis. Eur Respir J 2004;23:526531.

6 Verbanck S, Schuermans D, Paiva M, Meysman M, Vincken W: Small airway function improvement after smoking cessation in smokers without airway obstruction. Am Respir Crit Care Med 2006;174:853-857.
} 